\title{
Development and characterization of a highly selective hydrogen sensor system
}

\author{
Pramit Sood ${ }^{1}$, Jens Zosel ${ }^{1}$, Michael Mertig ${ }^{1,2}$, Wolfram Oelßner ${ }^{1}$, Andreas Klockow ${ }^{1}$, Olaf Herrmann ${ }^{3}$, \\ Michael Woratz $z^{3}$ \\ ${ }^{1}$ Kurt-Schwabe Institut für Mess- und Sensortechnik e.V. Meinsberg, \\ Kurt-Schwabe-Straße 4, 04736, Waldheim, Deutschland \\ ${ }^{2}$ Technische Universität Dresden, Professur für Physikalische Chemie, Mess- und Sensortechnik, \\ 01062 Dresden, Deutschland \\ ${ }^{3} \mathrm{ACl}$ Analytical Control Instruments $\mathrm{GmbH}$, Volmerstr.9, 12489 Berlin, Deutschland
}

\begin{abstract}
Distributed use of hydrogen $\left(\mathrm{H}_{2}\right)$ has grown with its increasing application in the mobility and energy sector. The need for highly sensitive, selective, long-term stable and miniaturized $\mathrm{H}_{2}$ sensor systems is essential for the safety and quality management of a future $\mathrm{H}_{2}$ supply chain. The present contribution reports on the development and characterization of a $\mathrm{H}_{2}$ sensor system based on a solid-electrolyte flow-through cell (8 mol.-\% yttria-stabilized zirconia, YSZ) operated in coulometric mode and combined with gas chromatographic (GC) pre-separation. Miniaturization of system components and results on parametric characterization are provided. A valve injection system for gas sampling was developed as a stainless steel 3D-printed valve manifold with miniaturized solenoid valves. The GC column oven (heating/cooling module) was accomplished using resistive heating and forced convective cooling of an cylindrical carrier. Both design concepts are reported together with results of their performance. A commercial solid electrolyte coulometric detector (SEC) was characterized under different operating conditions, i.e. at different detector temperatures, oxygen partial pressures, injected $\mathrm{H}_{2}$ concentrations and carrier gas flowrates, to gain insights into the essential sensor parameters like $\mathrm{H}_{2}$ peak attributes, accuracy and long-term stability.
\end{abstract}

Keywords: Safety monitoring, hydrogen sensor system, yttria-stabilized zirconia (YSZ), solidelectrolyte coulometry, gas chromatography

\section{Introduction}

Hydrogen has been widely used in chemical industry as well as petrochemical refineries for a century [1]. An increasing recognition of hydrogen as a clean energy source has extended it's application to various other fields. On the one hand, it is increasingly used in the e-mobility sector after transformation in fuel cells [2]. And, on the other hand, its importance is growing rapidly in a mixed energy infrastructure, where hydrogen is being produced from renewable energy sources (e.g. power-to-gas technologies) $[3,4]$. These applications have resulted in the decentralization of the hydrogen supply chain [5] in the context of production (electrolyzer facilities), transport (integrated with natural gas distribution pipelines) and various end users.

Because of its wide flammability/explosion range in air and small molecular size, hydrogen poses potential danger due to leakage. A widely used risk management approach in safety monitoring applications is to reliably and selectively detect hydrogen at trace concentrations $(<10 \mathrm{vol}$.-ppm) at start of a leakage [6].
Above-mentioned requirements dictate the need for more sensitive, selective, and longterm stable sensor systems, which can be miniaturized for flexible field installations. In [7, 8], different commercial sensor technologies and test methods are described and evaluated for hydrogen detection in safety applications. In [9-11] the usage of a solid-electrolyte-based coulometric gas sensor as a GC detector is described, which is capable to detect trace concentrations of oxidizable gas components $\left(\mathrm{H}_{2}\right.$, $\mathrm{CH}_{4}$ ) in the presence of air. The detector measures the titration current, which is related to the gaseous analyte concentration. The analytes are oxidized or reduced at the triple phase boundary (TPB) of the SEC electrode (Pt/YSZ/gas phase), which is polarized versus a Pt-air reference electrode to establish a constant low oxygen partial pressure in the carrier gas [10]. Eq. 1 describes the relation between the amount of analyte $x$ and the detector signal I based on Faraday law:

$$
x=\int_{t_{S}}^{t_{E}} \frac{\left(I-I_{B L}\right)}{z \cdot F} \cdot d t
$$


where $t_{S}$ and $t_{E}$ are the starting and ending times of the peak, respectively. $F$ denotes the Faraday constant, $I_{B L}$ stands for the baseline current and $z$ stands for the number of electrons transferred in the reaction.

The detector was characterized and optimized in terms of material properties and instrumentation related noise sources to enable selective measurement of $\mathrm{H}_{2}$ concentrations down to 0.2 vol.-ppm [10, 12]. The present contribution describes the design and test of some essential components of a miniaturized chromatographic measuring system with a SEC, to develop a miniaturized field device. It also reports the results from operational characterization of a commercially available SEC as test platform for future improvements and design optimizations.

\section{Experimental}

\subsection{Detector characterization}

Fig. 1 shows a scheme and a picture of the existing measurement system. A commercial GC (8610C, MG \#1, SRI Instruments Europe $\mathrm{GmbH}$, Bad Honnef, Germany) was modified by adding a SEC with temperature control $(F)$ and purpose-built potentiostatic circuit (E) as described in [10]. The gas sample injection system is enabled through a 10-port rotational valve $(A)$ and $1 \mathrm{~mL}$ sample loop. The sample is separated in a temperature programmed air bath oven $(B)$ containing a combination of molecular sieve $13 \mathrm{X}$ and silica gel stainless steel (SS) packed columns (length: 2m; OD/ID: $1 / 8 " / 2.1 \mathrm{~mm}$ ) and analyzed using a commercial SEC (D) (O2-DF-28.0 from ZIROX Sensoren \& Elektronik $\mathrm{GmbH}$, Greifswald, Germany). The separation process is described in detail elsewhere [13]. Nitrogen $\left(\mathrm{N}_{2}\right)$ of quality 5.0 was used as carrier gas. The sample loop was continuously flushed with sample gas mixtures, prepared with calibrated mass flow controllers (G) from Brooks Instruments (Hatfield, USA) using test gases with 1000 and 102.7 vol.-ppm $\mathrm{H}_{2}$ in synthetic air.

For the characterization of the essential sensor parameters like peak behavior, sensitivity, accuracy and reproducibility, the measurement system was inspected at different detector temperatures $\left(600-750{ }^{\circ} \mathrm{C}\right)$, oxygen partial pressures/polarization voltages $(-300 \mathrm{mV}$ to -450 $\mathrm{mV}$ ), injected $\mathrm{H}_{2}$ concentrations (0.2 - 180 vol.ppm) and carrier gas flowrates ( 6 - 16,5 $\mathrm{mL} / \mathrm{min})$. All chromatograms were recorded at a sample loop volume of $1 \mathrm{~mL}$, sample loop temperature of $60 \pm 1^{\circ} \mathrm{C}$ and ambient pressure conditions.
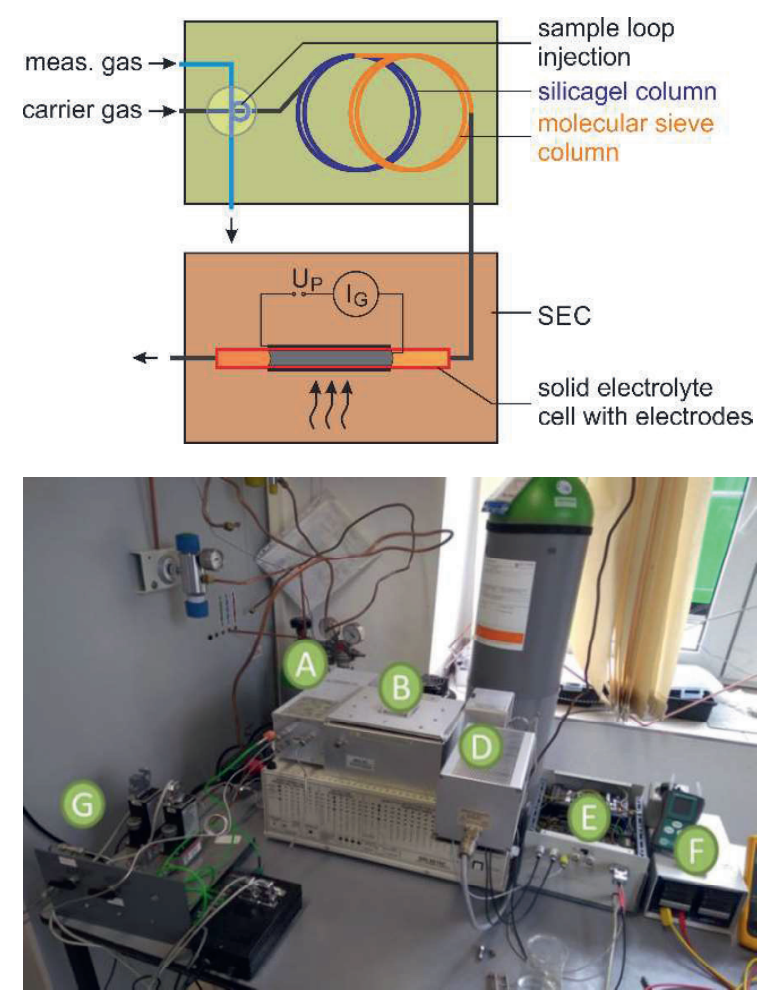

Fig. 1: Scheme (above) and picture (below) of the present measurement system, letter labelling is described in the text.

\subsection{Component miniaturization}

For the sample loop injection, a miniaturized SS valve manifold was developed, which is equipped with 8 miniaturized solenoid valves (S0705DX-CO, 3/2 way solenoid valves, SMC $\mathrm{GmbH}$, Germany) mounted on the manifold for flow actuation. A schematic of the concept is shown in Fig. 2. It also shows a laboratory prototype which was manufactured by 3D-printing (AM Metals $\mathrm{GmbH}$, Freiberg, Germany). The manifold was tested for gas tightness of the external fittings and internal channels, using helium leak test system (ASM 310, Pfeiffer Vacuum, Asslar, Germany). To characterize the gas dispersion in the manifold, it was connected to carrier $\left(\mathrm{N}_{2}\right)$ and sample gas flows $(0.1 \mathrm{vol} .-\%$ $\mathrm{H}_{2}$ in $\mathrm{N}_{2}$ ) as well as to a commercial SEC detector, operated by a potentiostat (Interface 1000, Gamry Instruments, Warminster, USA) and a sample loop with the volume $1 \mathrm{~mL}$. The column ports were short-circuited. Subsequently the coulometric current peaks were measured at this arrangement. Potentiostatic scans with multiple load and injection steps were performed at different detector temperatures $\left(600-650{ }^{\circ} \mathrm{C}\right)$, carrier gas flowrates $(10-50 \mathrm{~mL} / \mathrm{min})$ and injected $\mathrm{H}_{2}$ concentrations (10 - 300 vol.-ppm). 

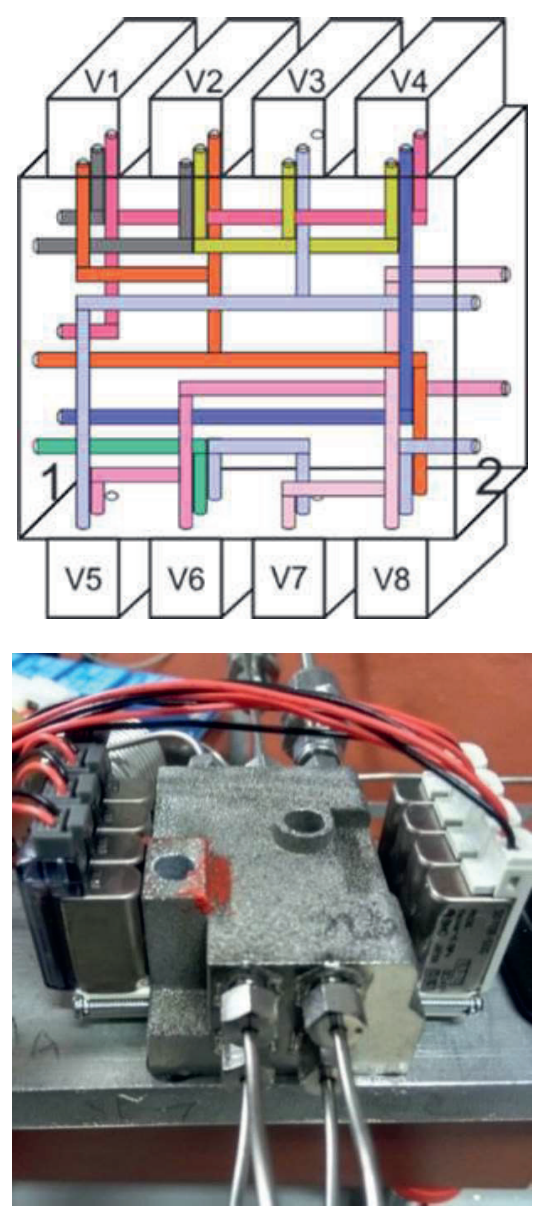

Fig. 2: Flow circuitry (above) of the miniaturized 3D-printed valve manifold $\left(45 \times 35 \times 25 \mathrm{~mm}^{3}\right)$, where 1) shows connections to sample loop, measuring gas, carrier gas and detector and 2) shows connections to columns, below: prototype for laboratory tests.

Fig. 3 shows the design concept and the corresponding prototype of a miniaturized column heating/cooling module (HCM). The GC columns were wound upon an aluminum (Al) cylinder as carrier together with an isolated heating wire (ThermoExpert $\mathrm{GmbH}$, Stapelfeld, Germany) and a Pt-200 temperature sensor (Heraeus Sensor Technology $\mathrm{GmbH}$, Kleinostheim, Germany). A silicon free heat conductive paste (Techtronix $\mathrm{GmbH}$, Cologne, Germany) was applied to ensure uniform thermal contact. The Al carrier is equipped with an embedded heat sink structure and cooled by an axial fan. The columns were thermally isolated with glass wool (not shown). The performance of the prototype was evaluated by heating/cooling cycles with constant or increasing heating power. The influence of a swing-type flap at the outlet of the cylindrical Al-carrier was tested as well. The cooling cycle was recorded always at maximum power of the axial fan.

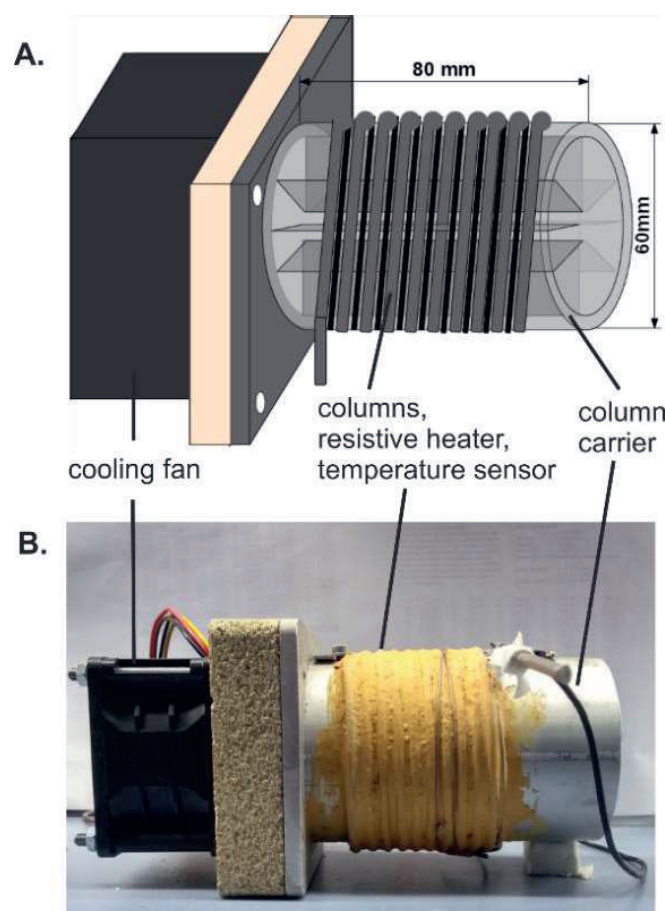

Fig. 3: Scheme (A) and picture (B) of a miniaturized heating/cooling module for the columns.

\section{Results}

\subsection{Effect of detector temperature and polarization voltage}

Fig. 4 shows hydrogen peaks measured at different SEC temperatures. The peaks were measured at constant polarization voltage and injected $\mathrm{H}_{2}$ concentration. The average carrier gas flow rate was adjusted to $10.5 \mathrm{~mL} / \mathrm{min}$ at standard conditions (= standard cubic centimeters per minute, $\mathrm{sccm}$ ).

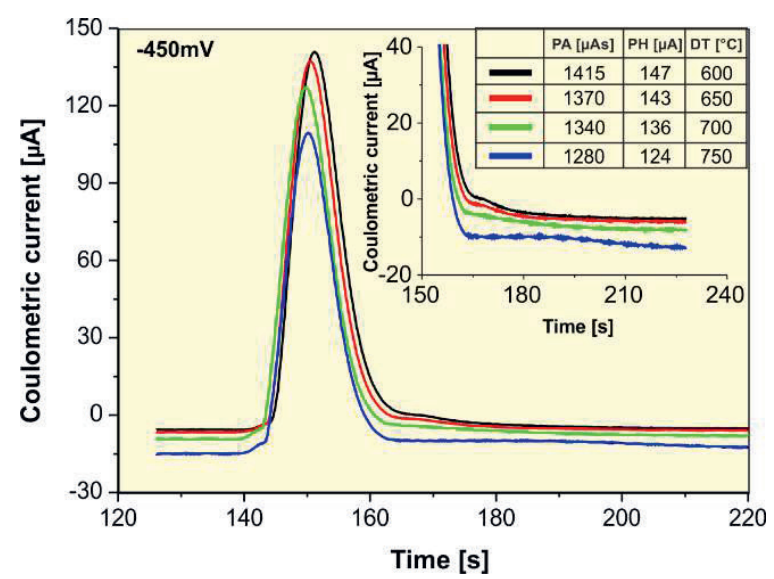

Fig. 4: Chromatogram segment showing $\mathrm{H}_{2}$ peaks and dependence of their peak areas (PA) and peak heights $(P H)$ on detector temperatures (DT), at polarization voltage $=-450 \mathrm{mV}, \mathrm{c}\left(\mathrm{H}_{2}\right)=180$ vol.-ppm in synthetic air. 
The results show a decrease of the $\mathrm{H}_{2}$-related peak area and peak heights with increasing detector temperatures. A closer look at the coulometric currents in the time segment between 160 and $200 \mathrm{~s}$ in the inset of Fig. 4 indicates an apparent peak tailing, which prolongs with increasing SEC temperature. This peak tailing indicates a $\mathrm{H}_{2}$ storage near the triple phase boundary (TPB) of the detector at higher temperatures. It is assumed that this temporary $\mathrm{H}_{2}$ storage (approx. $10 \%$ if the peaks at 750 and $600^{\circ} \mathrm{C}$ are compared) occurs at the electrode/electrolyte interface. As illustrated in Fig. 5 this interface consists of a porous YSZ layer sintered onto the YSZ tube to increase the TPB at the surface of the $\mathrm{Pt}$ wire mesh electrode. The stored $\mathrm{H}_{2}$ subsequently elutes from this layer and results the tailing. This phenomenon could be correlated to the findings reported in [14] where an increase of peak heights and areas was seen with increasing temperatures in cyclic voltammetry (CV) investigations on an identically constructed detector at comparable flow rates of measurement gas. The peak tailing duration at $750{ }^{\circ} \mathrm{C}$ prevents the complete peak integration since the following oxygen peak limits the integration time. At $600^{\circ} \mathrm{C}$ the amount of charge found in the peak corresponds to the injected amount of $\mathrm{H}_{2}$ according to Eq. 1.

To investigate the peak dependency on oxygen partial pressure $\left(\mathrm{pO}_{2}\right)$, different polarization voltages from $-300 \mathrm{mV}\left(\mathrm{pO}_{2}=25 \mathrm{mPa}\right)$ to $-450 \mathrm{mV}\left(\mathrm{pO}_{2}=0.27 \mathrm{mPa}\right)$ were applied. As shown in Fig. 6 , the described peak tailing can be observed at all applied polarization voltages, indicating that the $\mathrm{H}_{2}$ storage is occurring in a broader range of $\mathrm{p}\left(\mathrm{O}_{2}\right)$. No other influence of the polarization voltage is visible.

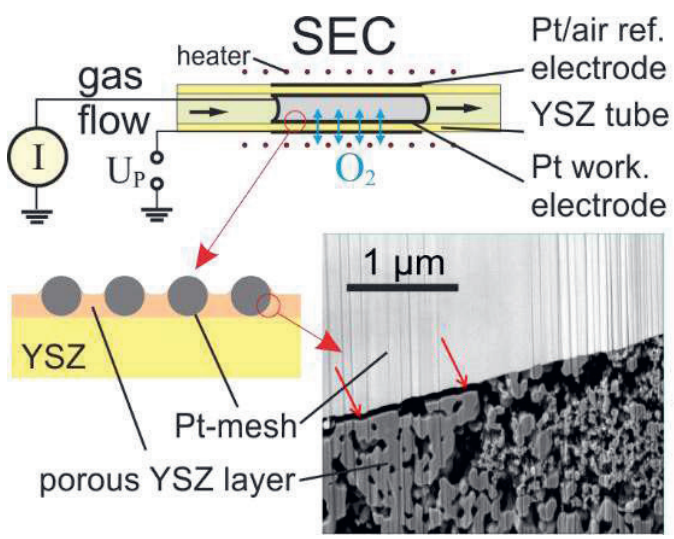

Fig. 5: $\quad$ Scheme of the solid electrolyte cell in the SEC and SEM image of the interface between the Pt mesh electrode and the porous YSZ layer situated between electrode and YSZ electrolyte to enhance TPB.

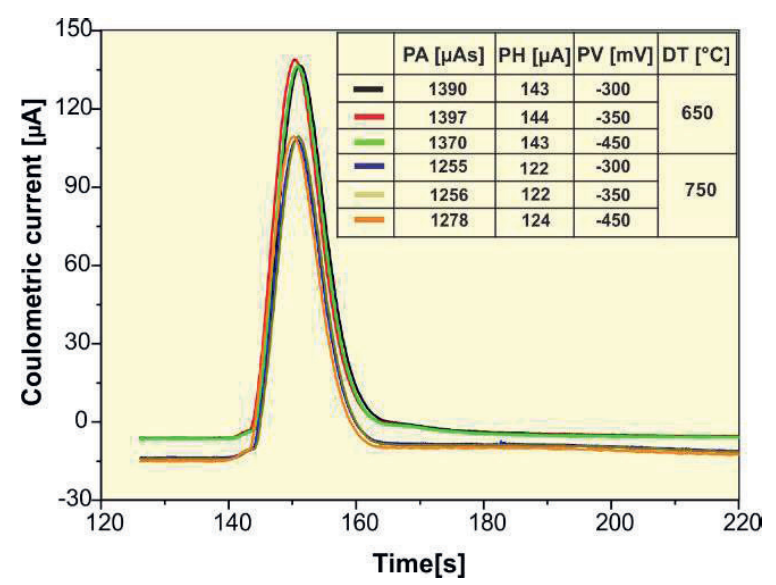

Fig. 6: $\quad$ Chromatogram segment showing $\mathrm{H}_{2}$ peaks and dependencies of peak area (PA) and peak height (PH) on polarization voltage $(P V)$ at two detector temperatures (DT), $c\left(H_{2}\right)=$ $180 \mathrm{vol}$.ppm in synthetic air.

\subsection{Peak behavior at different hydrogen concentrations}

The SEC was tested for chromatographic peak behavior and detection uncertainties at different injected $\mathrm{H}_{2}$ concentrations in the range $2-$ 180 vol.-ppm. The detector response was recorded for varying detector temperatures between $600-750{ }^{\circ} \mathrm{C}$ at constant polarization voltage $-450 \mathrm{mV}$. The resulting chromatogram segments given in Fig. 7 indicate that the peak tailing, described in Section 3.1, occurs at all measured concentrations. In addition, front-end and back-end shoulders are observed at concentrations $<50$ vol.-ppm. This effect is mainly caused by the gas chromatographic columns. It vanishes at trace concentrations $<10$ vol.-ppm.

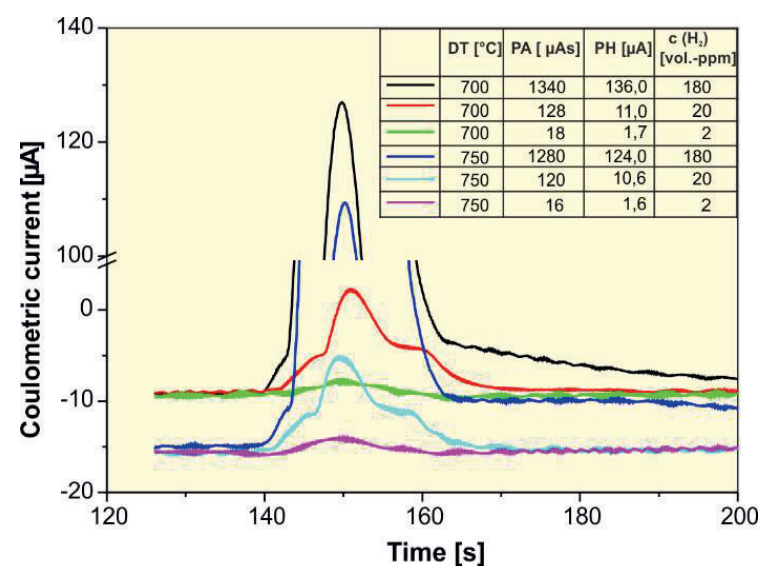

Fig. 7: Chromatographic $\mathrm{H}_{2}$ peaks with their peak areas (PA) and peak heights $(\mathrm{PH})$ at varying injected $c\left(\mathrm{H}_{2}\right)=2-$ 180 vol. - ppm, polarization voltage $=$ $-450 \mathrm{mV}$, detector temperature $(D T)=$ 700 and $750{ }^{\circ} \mathrm{C}$. 


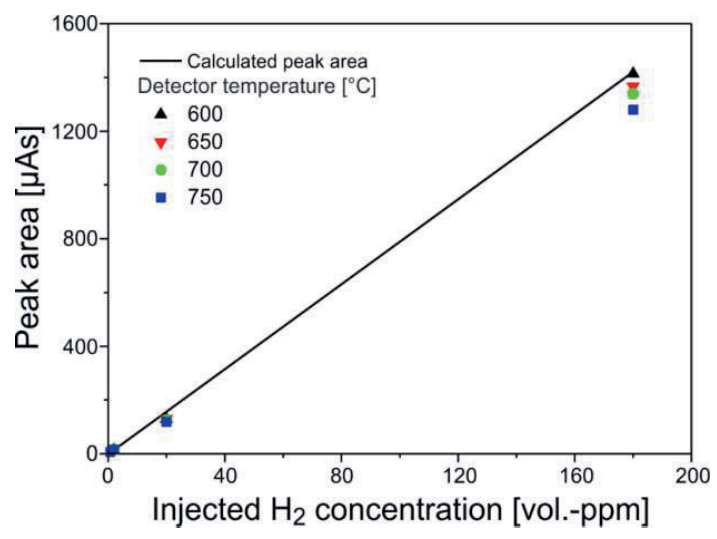

Fig. 8: Comparison between peak areas calculated by Faraday law (line) and peak areas derived from chromatograms at different temperatures and $\mathrm{H}_{2}$ concentrations (dots).

The peak areas measured in different experiments were summarized with respect to the analyte concentration as shown in Fig. 8. The results prove that the measured peak areas follow Faraday law closely within the accessible precision at $600{ }^{\circ} \mathrm{C}$. Due to the above mentioned storage effect a deviation of around $4 \%$ was found at $750^{\circ} \mathrm{C}$.

\subsection{Influence of carrier gas flow rate}

The hydrogen peak parameters were evaluated at varying carrier gas flow rates. Fig. 9 shows these results at two selected detector temperatures. The results in Fig. 9 reveal that with increasing flow rate, the peak height (and correspondingly the signal-to-noise ratio) increases while peak width and retention time decrease as expected. The peak area does not change.

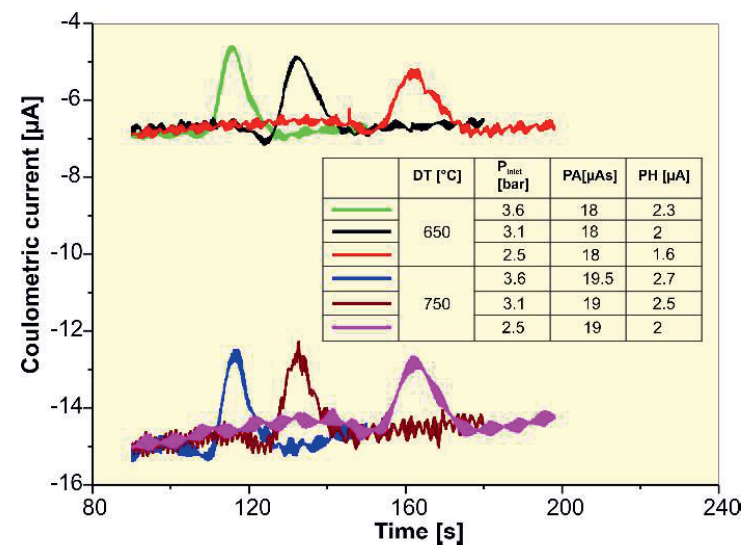

Fig. 9 Chromatogram segments showing $\mathrm{H}_{2}$ peaks and dependency of $\mathrm{H}_{2}$ peak areas (PA) and peak heights $(P H)$ on carrier gas inlet pressures $p_{\text {inlet }}=2-3.6$ bar (flowrates $=6-16 \mathrm{~mL} / \mathrm{min}$ ), $c\left(H_{2}\right)$ $=2$ vol. $-p p m$; polarization voltage $=$ $-450 \mathrm{mV}$; detector temperatures (DT) $=650$ and $750^{\circ} \mathrm{C}$.
The neglectable deviations between the measured peak areas indicate that the detector oxidizes the incoming hydrogen completely at all investigated flow rates. This result is supported by the findings at a similar SEC given in [10]. These insights will be used for optimizing parameters like carrier gas flow rate, detector geometry, peak retention time, signal-to-noise ratio and completeness of $\mathrm{H}_{2}$ conversion. They would also play a key role in further diminishment of the lower limit of detection (LLOD) and size of the measuring system.

\subsection{Characterization of miniaturized components}

\subsubsection{Valve injection system}

The newly developed injection manifold was characterized with respect to overall gas tightness and sample dispersion after injection. The leakage rates amount roughly to $10^{-8} \mathrm{mbar} \cdot \mathrm{L} / \mathrm{s}$. The average values of open circuit potentials (OCP) at tested carrier gas flow rates and detector temperatures indicate oxygen concentrations between $0.3-0.7$ vol.-ppm. Fig. 10 shows experiments performed with the manifold with different flow rates of the carrier gas. The illustrated sections of different potentiostatic scans contain one injection event. The stable baseline current proves an appropriate gas tightness of the prototype. As expected, the $\mathrm{H}_{2}$ peak height increases with flow rate while the peak area remains constant. Furthermore, the $\mathrm{H}_{2}$ peaks show an acceptable tailing, which indicates remaining possibilities to reduce dead volumes in the manifold and the fittings. Another evidence for these dead volumes are negative oxygen peaks, occurring after the first several actuations from inject to load events. These negative peaks decrease rapidly and vanish after 4-6 injections due to the ongoing flushing of these dead volumes.

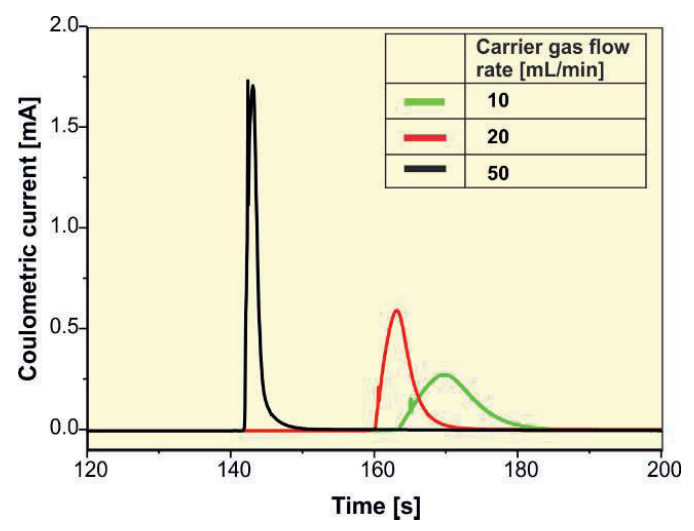

Fig. 10: Sections of potentiostatic scans at different flow rates, showing $\mathrm{H}_{2}$ peaks at one injection step, polarization voltage $=-300 m$ V , detector temperature $=600{ }^{\circ} \mathrm{C}, \mathrm{c}\left(\mathrm{H}_{2}\right)=300$ vol. - ppm . 


\subsubsection{Heating/cooling module (HCM)}

The temperature courses illustrated in Fig. 11 were obtained by heating and cooling the prototype shown in Fig. 3. The measured temperature gradients during heating $\left(10^{\circ} \mathrm{K} / \mathrm{min}\right)$ and cooling $\left(\sim 55^{\circ} \mathrm{K} / \mathrm{min}\right)$ already meet the desired values for final operation. Furthermore, the temperature gradient can be stabilized if the heating power increases linearly with temperature. As expected, the heating efficiency can be increased significantly by installing a swing-type flap at the outlet of the cylindrical Al-carrier (acting as a heat trap), which is closed during heating and opened by airflow during cooling.

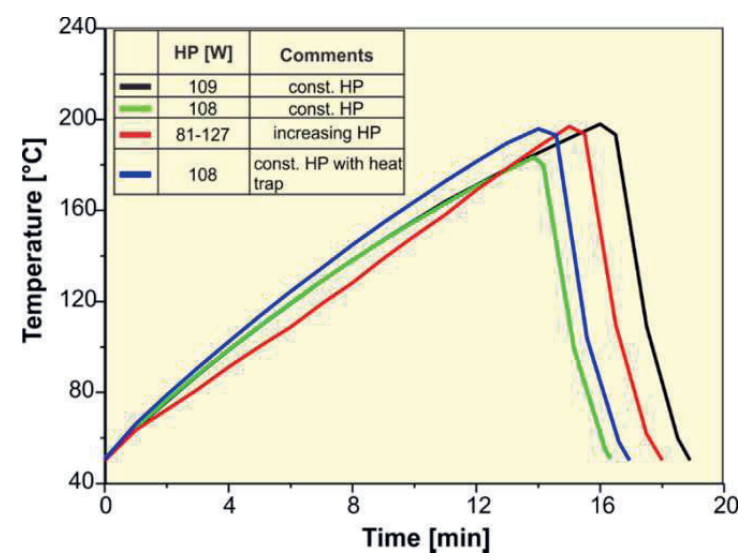

Fig 11: Heating/cooling ramps measured at the prototype given in Fig. 3 at different operating conditions as listed in the inset table, HP = heating power.

\section{Conclusions}

In this work, the response of a commercial solid electrolyte coulometric detector (SEC) was investigated at different operating conditions like temperature, oxygen partial pressure, injected $\mathrm{H}_{2}$ concentration and carrier gas flow. The observed results enable method and component optimization for improvement of selectivity, long-term stability and lower limit of detection.

At detector temperatures above $700{ }^{\circ} \mathrm{C}$ a pronounced $\mathrm{H}_{2}$ peak tailing was observed, which indicates temporary storage and slow release of $\mathrm{H}_{2}$. It is assumed that this storage occurs in a porous ceramic layer between the electrode and the electrolyte. This result is supported by dynamic measurements with cyclic voltammetry at a similar detector.

This tailing can be prevented almost completely by diminishing the volume of the porous layer or by decreasing the detector temperature. The peak areas measured at different $\mathrm{H}_{2}$ concentrations and detector temperatures demonstrated a close agreement with Faraday law at $600{ }^{\circ} \mathrm{C}$ and a peak area decrease of about $4 \%$ at $750^{\circ} \mathrm{C}$. The separation reproducibility could be quantified with the standard deviation of retention time $=1.5 \mathrm{~s}$. The repeatability of the whole system results in a standard deviation of the measured peak areas of $<2 \%$ for the $\mathrm{H}_{2}$ concentration 180 vol.-ppm. This outstanding detector stability enables its calibration free operation over long periods. The constancy of peak areas in the investigated carrier gas flow range proves the completeness of $\mathrm{H}_{2}$-conversion during the passage through the electrolysis cell. The results offer a test reference for the various construction tradeoffs between electrode geometry (length and cross section area) and chosen flow rates.

The limit of detection of the system was quantified to range at around $200 \mathrm{vol}-\mathrm{ppb} \mathrm{H}_{2}$. A further diminishment of this parameter is expected with a newly developed miniaturized detector.

A miniaturized sample injection system was developed and manufactured as a 3D-printed manifold made of stainless steel. It is equipped with side-mounted miniaturized solenoid valves. The manifold tests show reproducible and stable $\mathrm{H}_{2}$ peaks and drift-free baseline current. Main advantages of this, more than $40 \%$ miniaturized, injection system are an increased flexibility enabling intelligent injection procedures and significant cost reduction.

A cylindrical carrier was developed and tested for resistive heating and forced convection cooling of separation columns. It provides more than $50 \%$ size reduction and meets the requirements of the chromatographic method.

\section{Acknowledgements}

The presented work was carried out within a research project funded by the Federal Ministry of Education and Research under the support code 03ZZ0724A. The authors are responsible for the content and acknowledge the funding. Furthermore, the authors would like to thank CS Chromatographie Service $\mathrm{GmbH}$, Langerwehe, and Zirox- Sensoren \& Elektronik $\mathrm{GmbH}$, Greifswald, for professional and device related support. The material related investigations and analysis done by F. Altmann and his team at Fraunhofer Institute for Microstructure of Materials and Systems IMWS in Halle is gratefully acknowledged.

\section{References}

[1] R. Ramachandran, R.K. Menon, International Journal of Hydrogen Energy 23, 593-598 (1998); doi: 10.1016/S0360-3199(97)00112-2

[2] T. Sinigaglia, F. Lewiski, M. Eduardo, S. Martins, J. Cezar, M. Siluk, International Journal of Hydrogen Energy 42, 2459724611(2017): doi: 10.1016/j.jhydene.2017.08.063

[3] A. Maroufmashat ,M. Fowler, Energies 10, 1089 (2017); doi: 10.3390/en10081089 
[4] D. Ferrero, M. Gamba, A. Lanzini, M. Santarelli, Energy Procedia 101, 50-57(2016); doi: 10.1016/j.egypro.2016.11.007

[5] J. M. Ogden, Annual. Review of Energy and the Environment. 24, 227-279 (1999); doi: 10.1146/annurev.energy.24.1.227

[6] ISO 26142, Hydrogen detector apparatusstationary applications, 2010.

[7] W. J. Buttner, M. B. Post, R. Burgess, C. Rivkin, International Journal of Hydrogen Energy 36, Issue 3, 2462-2470 (2011); doi: 10.1016/j.ijhydene.2010.04.176

[8] R. O. Cebolla, E. Weidner, W. Buttner, C. Bonato, K. Hartmann, K. Schmidt, International Journal of Hydrogen Energy 43, 21149-21160 (2018) doi: 10.1016/j.ijhydene.2018.09.107

[9] J. Zosel, M. Schelter, V. Vashook, U. Guth, Tagungsband (2012), 324-331, doi: 10.5162/sensoren2012/3.2.4

[10] M. Schelter, J. Zosel, W. Oelßner, U. Guth, M. Mertig, Sensors and Actuators B 187, 209-214 (2013); doi: 10.1016/j.snb.2012.10.111

[11] K. Teske, P. Popp, J. Baumbach, Journal of Chromatography 360, 417-420(1986); doi: 10.1016/S0021-9673(00)91690-X

[12] M. Schelter, J. Zosel, V. Vashook, U. Guth, M. Mertig, Solid State Ionics 288, 266-270 (2016); doi:10.1016/j.ssi.2016.01.020.

[13] https://srigc.com/cn/downloads/ 29/MG1man.pdf

[14] A. Ruchets, N. Donker, D. Schönauer-Kamin, R. Moos, J. Zosel, U. Guth, M. Mertig, Sensors and Actuators B: Chemical 290, 53-58 (2019); doi: 10.1016/j.snb.2019.03.063 